\title{
ASSESSMENT OF THE USE OF INFORMATION AND \\ COMMUNICATION TECHNOLOGY IN THE \\ IMPROVEMENT OF PERFORMANCE AND \\ EFFICIENCY IN THE BANKING SECTOR: \\ A CASE STUDY OF THE NATIONAL MICRO FINANCE \\ BANK (NMB) DAR ES SALAAM
}

\author{
Rehema Chande-Mallya \\ Muhimbili University College of Health Sciences (MUCHS)
}

\begin{abstract}
This paper examines the extent of ICT usage and application in banking institutions and the extent to which ICT has improved efficiency and performance in the National Microfinance Bank (NMB) in Dar es Salaam region. Findings of this paper revealed that ICT has improved performance, efficiency and record keeping in aspects like fast access to customer information and to some extent, its retrieval. However, there are shortcomings also which the study revealed like lack of technical service support, power failures and interruptions as well as inadequate IT facilities particularly in the bank branches. Based on the findings, it is recommended that $N M B$ should identify critical training needs and invest in staff training to ensure that they have up to date IT skills and knowledge about relevant software in order to cope with software changes as well as competitions. Furthermore, in order to stand competition in its branches, the NMB should invest in ICT hardware and software in branches rather than concentrating on the headquarters only.
\end{abstract}

\section{Introduction}

In the $21^{\text {st }}$ Century, there has been a considerable debate on the benefits of Information and Communication Technology (ICT) application. This has been a result of the changes that ICT has brought to various sectors like business, health, education, industry, agriculture just to mention a few. Sahaya and Walshen (1995) for example, argue that for many nations ICT has played a leading role in the $20^{\text {th }}$ Century information revolution. In this era, science and technology are becoming the critical factors of the so called value added economy. There has therefore been an increased interest and awareness on a wide range of issues, including ICT industries or its acquisition, use, maintenance, sustainability, education requirements and ICT standards. This development has inspired many nations, institutions and individuals to learn apply and exploit ICT for social, economic and business purposes. 
The computer technology is referred to as "the machine that changed the world" (Lucas, 1997). It is clear that Information and Communication Technologies (ICT) continue to revolutionize every sector and aspect of our lives. For example, Lucas (1997) points out that contributions provided by ICT's in business organizations include:

- New ways to design organizations

- Creates new relationships between customers and management

- Enables tremendous efficiencies in production and services

- Changes the basis of competition

- Provides mechanism through groupware for coordinating work and creating knowledge base of organization

- Provides the manager with electronic alternatives face-to-face communications and supervision

Developed countries have made a tremendous leap forward in the use and application of ICT in all sectors. Similarly, in developing countries ICT is being applied in economic key sectors, financial institutions, industry, communication, health, transport, and education sectors to improve efficiency and quality of life. In these countries, especially developing countries ICT is increasingly changing the working culture and also providing fast access to information and its retrieval, communication and transfer.

In Africa ICT technology has not gained the same momentum compared to developed countries in its use and application, instead the continent has been lagging behind in its adaptation. Although the pace of ICT adoption in developing countries and for different activities seems rather slow, there is, however, evidence to suggest that there are apparent efforts to use and apply ICT at national and individual levels. Major factors or problems limiting the wide spread and use of ICT in developing countries include among other things, lack of funding, expertise, political and cultural factors, bureaucracy, lack of ICT technical and managerial skills and also poor economies of the continent.

Similarly, Quicken (1997:6) argues that, dependence on Foreign aid in ICT has some disadvantages for example:

- The recipient can be controlled with an ICT system that has been given to him and that works for a while but when problems appear he does not know where to turn to, because he is not familiar with the IT infirastructure.

- The learning process is less in comparison with installing ICT on ones own initiative. 
However, despite the above disadvantages, donor funding is important because it ensures recipients access to ICT, creates and stimulates IT awareness in recipient countries which influences the economy of a country, for example productivity, employment and competition. It also influences equality within a country.

\section{Application and use of ICT in Tanzania}

The adoption of the computer technology has brought most services closer to customers worldwide and has made it possible to handle huge amount of transactions in a very short time.

Tanzania has experienced a gradual growth in ICT use especially computers since the 1960s. Literature indicates that the first computer was installed in the treasury back in 1965 . The growth has continued rapidly in the $1980 \mathrm{~s}$, especially with the liberalization policy, which allowed more influx of all types of goods and services (Baker, 1993).

A study conducted by Sheya and Koda reveals that, in 1978 there were about 5 mainframes and 7 microcomputers. By 1984, there were about 13 mainframes, 15 minis and 79 micros in the country. In 1986 the number of micros had increased to 470 , minicomputers to 53 and main frames to 16 . By the second quarter of 1993 more than 570 computers were imported. The application of computers in Tanzania started about two decades ago mostly in big institutions.

Studies show that, in 1965, the first computer was installed in the government treasury followed by mainframe computers in 1972, purchased and installed in several parastatals. Among them are TANESCO, STC (State Trading Cooperation) and NPF.

Today globalization of the economy calls for greater efficiency, effectiveness, quick production for maximizing profit and highly qualified personnel with up to date skills. Therefore, the introduction and use of IT is inevitable because, according to Rowley (1995:5), the introduction of computer may be viewed as a means of saving staff time and money. In this context, developing countries are compelled to adopt technological changes so as to match with the world development trends.

Tanzania like any other developing countries uses computer technology in social, economic and cultural spheres in order to facilitate production and other daily operations. 
According to a recent report (Esselaar, M 2001) ICT use and application in Tanzania is gaining momentum and the government has made considerable efforts to create a conducive environment for economic liberalization and foreign investments. However, in Tanzania, rapid integration of ICT in the economic and service sectors is constrained by many problems just as in other African countries. However, the government has shown by words and deed that it is committed to promoting IT usage in the country. For example, recently, the government abolished VAT on computer hardware and software. This and other policy reforms are now bearing fruits and are creating a conducive environment for increased importation and usage of computer technology and expediting its integration in all sectors including the banking sector.

\section{ICT use and applications in Financial Institution Tanzania}

As observed above, Tanzania has been experiencing a gradual growth in information technology, particularly in financial institutions and some public institutions. In the early 1960's, the financial sector had the largest market share of computer units at $18 \%$, which reflects the capital commitment that the banks have been making in their drive to automate. The Bank of Tanzania (BoT), Co-operative and Rural Development Bank (CRDB) and The National Bank of Commerce (NBC) have been leading in terms of computerization (Baker, 1993).

According to Diederen, Kemp and Muysken (1990:121), computer applications play an important role in financial institutions in developing countries because it facilitates storage of data, modifications in data as a consequence of payment transfer, withdrawal or deposits as well as networking throughout the country. Also, banks have relatively large funds at their disposal, hence they are able to invest in new technologies including software specialists, programmers and educational programs.

According to Broadbent (1990), computers have been applied mostly in the productive areas such as communication and automation, data management as well as computations. Diederen, Kemp and Muysken (1990:120) point out that,"... since the $1970 \mathrm{~s}$, the financial sector has been one of the branches of economic activity that has benefited most from the development of computer and communication technologies. Also, this sector including insurance and other business services use ICT at a relatively high rate.

This implies that the implementation of the new technology paradigm requires investment and even changes in institutional structures. 
Lewis and Davis (1987) observes that over the past 20 years the business of banking has been dramatically altered as evidenced by the rise of international banking, introduction of credit cards, debit cards, automated and teller machines. "...a great amount of transactions in the world are still made with cash or by cheque".

Saarinen (1999) points out that application of computers in developed countries especially in the banking sector has facilitated services and increased production. Furthermore, how a company uses (or does not use) technology is important for its long run survival. Product development, packaging, promotion, prices and distribution system are all influenced directly by technology. A firm that makes wrong decisions regarding technology may well lose out the competition. Poor decisions about technological forces may even drive a firm out of business.

Mayingu (1999:2) also observed that ICT is a tool that facilitates bank services to perform better and to achieve the primary mission and to create new products and services. He further argued that, those banks that fail to invest in current technology face the danger of becoming non-competitive by losing markets to better-equipped institutions. Globalization has forced banks to continue to invest in computer technology, so that they can provide the information and trading facilities and expand business opportunities for competitiveness.

The spread of computer use for networking and communication, electronic mail and files exchange and transfer using computer networks in Tanzania was introduced in 1996. This technology supports and improves effective delivery of reliable and quality services to the customers. According to Wendel and Chinn (2000:8), computer technology offers the more sophisticated competencies in financial institutions such as database marketing, efficient product delivery as well as customers advanced skills and knowledge. These show that today there are different services rendered by computers to facilitate business operations. Today almost all bank branches of the Microfinance Bank in Dar es Salaam use computer technology. This growth has been important in the creation of information technology base in Tanzania's Financial Institutions.

Sanga (1996) observed that, no financial institution could offer complete and satisfactory services to their customers without exploiting the environment of the Information Technology Infrastructure (ITI) services beyond its boundaries. This implies that there is a need to provide ICT requirements for any enterprise to be able to function effectively. Computers have also been used in banking as a competitive pressure force. 


\section{Research Methodology}

Data for this research was gathered using a combination of methods. This is considered the most appropriate method for obtaining reliable and valid data.

\section{Secondary data}

Extensive reading was done to enable the researcher to perceive and respond to issues discovered during the investigation. This included information from published and unpublished materials. The sources were the University of Dar es Salaam Main library, IFM library and The British Council library. Other reviews included online and offline research, books, annual reports, papers, journal articles and newspapers.

\section{Primary data}

Primary data was gathered through a survey using a structured questionnaire with both closed and open-ended questions, face to face interviews and direct observation. The questionnaire was administered to both staff and customers.

A total of 58 respondents participated in this study. These included bank staff and customers. Thirty-eight were NMB staff and twenty were NMB customers. Of these 30 were males and 28 were females. The NMB staff comprised of eleven supervisors, eight tellers/clerks, seven branch operation managers, six branch managers, one customer service manager, two senior system analysts/programmers, one IT manager and one business system officer. On the part of customers, three customers were conveniently selected from each of the six big branches. Two more customers came from the University of Dar es Salaam Agency and Muhimbili University College.

Questionnaires were administered to the bank staff and customers. This was done so as to include all the branches and to obtain more information concerning the extent to which ICT has improved efficiency and performance in Tanzania banking sector. A case study of NMB Bank in Dar es Salaam. There are 6 branches of NMB in Dar es Salaam and two agencies. 


\section{Findings of the Study}

\section{Major Services provided and ICT application}

The major services that NMB provides are customer services $10(26.3 \%)$, Credit and Deposit $9(23.7 \%)$, Loans $8(21.1 \%)$ and Money transfer 11 (28.9).

Findings revealed that $\mathrm{NMB}$ has computerized $29(76.3 \%)$ of its customer services functions, the rest are not computerized. NMB decided to computerize these functions to improve provision of efficient, quality and fast services to customers, and in order to be competitive. Most staff were concerned about losing their jobs due to computerization. However, some members of staff indicated that ICT was a challenge in that it has forced staff to learn new skills and it has also reduced workload for staff and the bank.

The bank involves, in IT applications components in its operations such as balance checks, money deposits, money credits, money transfers and loans and telecommunication infrastructure. The rapid diffusion of IT, is increasingly demanded by many banks like NMB as they realize that its potential has created major challenges for other banks.

Twenty five $(65.8 \%)$ respondents said that computerization had improved provision of services in branches, eight $(21.0 \%)$ said that computerization has improved accuracy of records and data while five $(13.2 \%)$ said that computerization has reduced workload for staff. Others said computerization has improved performance and efficiency in banking functions.

\section{Software Familiarity}

Nine (23.7\%) were familiar with "Easy bank" a software application commonly used to support banking operations. This was followed by DOS eight $(21.1 \%)$, Microsoft word and Linux three (10.5\%), PowerPoint, Microsoft Excel and COBOL, three (7.9) respectively. The least known software, application was Microsoft Access (2.6\%). However, $(7.9 \%)$ of the respondents did not answer this question. It is possible that the latter were not familiar with any of the listed software applications. These results also show that very few of the staff in NMB have been exposed to critical banking software applications and that there is a need for NMB to identify critical IT skills for NMB staff. In general, what these results show is that there is a need to train and expose staff to critical banking software applications in order to improve worker performance and efficiency. 
The findings revealed that most of the NMB staff need further skills so as to improve efficiency and effectiveness. For example eleven $(28.9 \%)$ of the respondents indicated that they would like to learn Computer programming, three (7.9\%) Easy bank, three (7.9\%) said Microsoft Excel, three $(7.9 \%)$ said Microsoft Word, two $(5.3 \%)$ said they needed to know Page maker, two (5.3\%) said they would like to learn about Data Management Software applications, one $(2.6 \%)$ said Internet searching, one $(2.6 \%)$ said DOS and one $(2.6 \%)$ said Microsoft Access. However, eleven $(28.9 \%)$ did not answer this question.

The results indicated that there is a need for NMB to identify critical software applications and skill levels needed by NMB to improve provision of quality and effective services.

\section{IT Policy}

Twenty-six (68.4\%) said that the NMB had an IT Policy, three (7.9\%) said they were not aware of such a policy while nine $(23.7 \%)$ said they did not know. Based on these findings, it is clear that NMB needs to publicize its IT policy to workers so that it can achieve its objectives. Knowledge of the policy would ensure that staff know what is expected of them and what they should expect from their employer in terms of their training requirements.

Respondents who said such a policy was needed provided a wide range of answers and indicated that an IT Policy would:

- Provide guidelines for day-to-day bank operations.

- Improve financial management capabilities of NMB

- Assists the Chief Executive in delegating day-to-day responsibilities for security to executive branches.

- Ensure accountability and a clear line of responsibilities.

- Provide guidelines for IT operations and applications at the headquarters and its branches.

- Ensure System Access control and prevent loses and an authorized system use that could potentially result in fraud or manipulation of NMB data or wrongful dissemination of information from the systems databases.

- Ensure that only authorized staff would have physical access to NMB IT hardware and software applications. This would prevent compromising information in NMB databases or damage.

- Ensure that the Bank puts in place mechanisms or guidelines for back up, operating and monitoring procedures, data output, log in and activity schedules. 
Problems encountered by respondents since computerization ranged from lack of IT skills $(18.4 \%)$, not familiar with some computer programs (31.6\%), inadequate ICT facilities (18.4\%), lack of technical service support $(7.9 \%)$, frequent power failure $(2.6 \%)$, frequent power interruptions $(7.9 \%)$ and no guiding policies $(2.6 \%)$.

In response to problems encountered the bank decided to train more IT personnel to handle both routine and specialized functions and strengthen its IT department. The banks also employed more trained IT experts to improve effective use of IT facilities and its functions. Due to frequent power cuts and power interruptions the NMB decided to purchase heavy duty generators to ensure smooth running of its functions. The generator switches on and off automatically in case of power failure.

Due to power fluctuations, many Companies and Industries have lost expens re irreplaceable equipment. To avoid this, most of the companies decided to purchase and install power surge protectors. In 2002 the Government employed new TANESCO management. Perhaps this move will, in the long run, improve provision of power supply in the country. In the meantime, NMB should also install power surge protectors. The Bank should also train technicians to provide technical services support. NMB branches, for example Temeke branch, should also be linked to Internet so as to improve its communications system and should be linked to all countries. Similarly, the NMB should purchase more ICT facilities to enable staff to get on the job training and experience.

\section{Areas of improvement for effective use of ICT banking}

Ten (26.3\%) out of thirty eight respondents said Customer service department, nine $(23.7 \%)$ respondents said more staff should be trained, four $(10.5 \%)$ said money transfer/telegraphic, three $(7.9 \%)$ said security of the program, three $(7.9 \%)$ said cash department, two $(5.3 \%)$ respondents said networking, two (5.3\%) said Internet service, this was a serious case in Temeke branch because there were no Internet services. The internet service is very important because a lot of information can be obtained including the exchange rates, also internet service facilitate communication within few seconds with other branches and one $(2.6 \%)$ respondents said IT department, this means more IT skilled personnel are needed to ensure proper functioning and strategic application of IT at NMB.

\section{Use of IT banking facilities at NMB}

Most banking services cannot be offered without computer technology. NMB staff said that they use the NMB banking facilities to check account 
balances, to withdraw money and to deposit and transfer money. Surprisingly, NMB does not offer the ATM services like other banks because according to the IT Manager, the installation was too expensive and as far as the customers were concerned most of NMB customers cannot afford to pay the service charges of ATM.

\section{Improving effective use of ICT}

Eight $(40.0 \%)$ respondents said the bank should invest in training of their staffs, eight $(40.0 \%)$ said the bank should employ skilled IT personnel, while three $(15.0 \%)$ said they don't know. Only one respondent said NMB should also train users how to effectively utilize IT facilities and services.

The findings of this study showed that ICT has improved performance, efficiency and 'provision of services including record keeping and fast access to information and retrieval, to some extent, but there were still some constrains. Problem mentioned include lack of IT skills, some of the staff were not familiar with the computer programs, inadequate facilities, lack of technical service support, frequent power failure and power interruptions and lack of guiding policies.

The findings also revealed that the bank needed to identify critical training needs and requirements and train staff in those areas to enhance their skills so as to improve the banks performance and efficiency. In addition the findings revealed that, while the headquarters was well equipped with ICT facilities, the branches had inadequate IT facilities which contributed to long queues. Similarly the findings revealed that the bank did not have a policy on IT to guide stuff in providing the good services so as to improve performance and efficiency.

An analysis of the status of ICT in the banking sector was important in the improvement of performance in the banking sector including NMB- Dar es Salaam, also in the identification of the different uses and applications of ICT in the NMB. The original study (Chande 2003) provided baseline data and information based on respondent's responses to the four research questions related to the problem. The questions were aimed at exploring in many dimensions of ICT application and use in banking institutions. The questions were aimed at establishing the extent of ICT usage in improving efficiency and performance in banking sector and these were:

1. What activities have been computerized in NMB?

2. To what extent has ICT usage improved performance and efficiency in banking activities?

3. What are the benefits of using ICT in NMB?

4. What major problems has NMB encountered since computerization? 


\section{Computerized functions}

There is a close relationship between computerization in its various forms and technological change. The benefits of computerization can be accurately viewed as a success when applied into different fields such as industrial, education, health, agricultural, business etc., in a most efficient and effective way to increase productivity.

In response to the first research question, staff mentioned different services such as money credit, deposit, loans and money transfer as having been computerized. They were of the view that computerization has improved the transfer of money electronically. This view is also shared by Rothman and Manasinghe (1989:33) who observed that:

Computer has made it possible to handle a huge amount of transactions in a very short time. These new opportunities and changes had an important effect on the organization of work such as in banking personnel.

\section{How ICT improved performance and efficiency in NMB bank}

The findings of this study show that ICT has improved performance and efficiency in NMB banking and computerization has brought services closer to customers worldwide. For example huge sums of money can be transferred electronically in a very short time. However, branch transactions are basically classified as cash, clearing and transfer. Transaction on current accounts can be classified as:

- Receipt of credit into the account

- Payment of cash/cheques across the counter

- Credit to the account arising out of collection of local clearing cheque

- Payment of cheque received through local clearing

- Transfer from/to the account, to/from another account at the branch or some other branch of the bank.

The range of banking services which can be delivered to customers by electronic technology has expanded extensively. Banks now use technology to transmit information, receive instructions from head office, transact and settle business. Whereas, prior to computerization everything was done manually and it took a long time to serve one customer, today customers have increased due to faster and more provision of efficient and accurate services. Prior to computerization data was stored in paper files but currently data is stored on computer databases which makes it easy to access and retrieve any information needed such as customer balances, deposits and credits, money transfers, loan services and balance-sheet statement. ICT therefore has changed the way business is done. 


\section{Benefits of using ICT in NMB}

As indicated earlier, computerization has improved banking services and the way business is done. Large number of customer can be attended much faster and at the'same time. The requirement of globalizations have forced banks to continue to invest in computer technology, so that they can provide the information and trading facilities and expand business opportunities.

Computerization has also increased privacy of customer's accounts and it has increased confidence in customers of the services provided. It has also attracted more customers compared to the old manual system. The extent of customer satisfaction is increasing in the big branches mainly through statements of accounts and payment of cheques. In addition it has improved proper record keeping, expedited customer services, transactions/money transfer, reduced chances of making forgeries and it has also increased staff morale.

Moreover, computerization makes the performance of reports easier since banks now require performance reports to be submitted to the head office by branches at monthly/quarterly intervals. This is a comprehensive report covering a wide range of branch activities. The report is analyzed to assess relative performance of branches, regions and zones on different items. The processing of this report can now be easily done on the computer system for processing the weekly abstract.

\section{Major problems NMB encountered since computerization of its activities/functions}

The findings show that NMB has also encountered problems. The followings are the problems, which were mentioned by respondents.

\section{Lack of IT skills}

One of the major problems cited is lack of IT skills. The findings show that most of NMB staff were not familiar with banking software applications. For example most were only familiar with banking operations (easy-bank) an application, which helps them to access and retrieve customer service information and its storage. Based on the findings it appears that training was not provided to both staff and users prior to computerization. Since then some key staff have been trained but they said they would benefit more from further training. This would improve their efficiency and performance in providing quality services and also ensure effective 
utilization of ICT facilities. Therefore, training is needed to cater for the needs of staff and customers.

\section{Inadequate facilities}

In 2000 several banks in Tanzania had introduced ATM systems. These include banks such as Standard Charted, CRDB, NBC, Stanbik etc. NMB has a strong demand for ATM services but according to the IT Manager the problem is that the installation of ATM was too expensive they cannot afford it. Furthermore, NMB was a local bank which means $90 \%$ of their customers are low class people who could not afford the cost of ATM services since customers have to pay service charges for every transaction.

Similarly, facilities at NMB are not enough to fulfill the needs of the bank especially at the customer service department where there is only one computer in a branch to save many customers one at a time. Therefore, it is believed that the bank will perform better when put in private hands so as to improve the services and also in order for the bank to be of the same standard as the other banks.

\section{Lack of technical service support}

This is a very serious problem. Due to lack of skilled/qualified IT personnel to provide technical support when things go wrong, bank branches have to wait for IT experts from the Head Office (IT department) to come and solve the problems. This leads to a wastage of time and money. But if there was at least one IT expert in each branch such problems would be solved within minutes. Sometimes customers go to the bank only to find there is no service and have to wait for a longtime until people from Head Office (IT skills) come and solve the problem.

\section{Staff training}

According to the Training Manager of NMB, there was a staff development policy of training their staff and this was in-house training which takes about five days only and also outside training for about 2 weeks. This training caters for the purpose of solving small problems. However, there were no long period trainings which are conducted for the staff unless under unpaid leave scheme which allowed for only few staff.

\section{Software applications}

As presented in Chapter 4, most of NMB staff are familiar with Easy bank software-bank operations, an application which helps them to access and 
retrieve customer service information and its storage. Therefore, application software are not adequate for the needs of customers and the bank, that's why training is being conducted in order to improve performance and efficiency in providing quality services.

\section{Frequent power cuts and power interruptions}

This was also another problem mentioned by the respondents. The generators were available only to some of branches such as Bank House, Ilala, Kariakoo, and Morogoro road, but the rest of the branches did not have generators, but according to IT Manager they were in the process of buying generators- (stand buy generators) which would switch on and off automatically in case of power failure.

\section{What can be done to promote effective use and application of IT in banking?}

In order to promote effective use and application of IT in banking, there is need to employ more skilled IT personnel and to train existing personnel in the branches so as to improve performance. Also there is a need to buy up to date computers which will cater for the needs of banking functions. Apart from that, the bank should invest more in IT at branch levels in order to provide effective and efficient services to customers including day to day banking operations and functions. This would reduce the long queues especially during the end of the month. Furthermore, the bank needs to conduct a needs assessment to determine the type and level of skills required as well as software needs and requirements.

\section{Conclusion}

Generally, in order to promote effective use and application in IT banking, there is a need to employ more skilled IT personnel and train the existing personnel in branches. Also the NMB bank needs to conduct a needs assessment to determine the types and levels of skills required as well as software needs and requirements. In addition, while the headquarters is well equipped with facilities, the branches are not; a factor which contributes to long queues. In view of this, the branches should be fully equipped with ICT facilities in order to improve performance, efficiency and customer satisfaction. 
Considering the performance and efficiency of ICT in banking institutions, the study recommends the following:

1. There was a need to train staff and users to ensure effective use of ICT in all NMB banks and in order to reduce long queues in branches;

2. All sections or departments of NMB bank should be computerized so that the organization can achieve its set goals;

3. ICT is changing fast, and as a result there are new versions being produced everyday ( Lisa 1996). The NMB should therefore be aware of new versions because these have programmes which are more advanced compared to older ones.

4. There is a need to promote ICT technology awareness to users not only in NMB bank but also in all financial institutions in Tanzania.

5. Due to power cuts NMB branches should buy stand by generators to ensure continuity in service provision.

6. NMB bank should employ competent ICT personnel to ensure effective and strategic use of ICT facilities.

\section{References}

Baker, S (1993). The Survey of Information Technology in Tanzania. Tanzania Commission for Science and Technology, Dar es Salaam, Tanzania

Broadbent, M (1990). "New Information Communication Technologies in Scientific Communication:" Implication for third world users. The Information Society 6 (3): 200-231

Chande, R (2003). Assessment of the extent of information and communication technology (ICT) improvement of performance and efficiency in the banking sector: A case study of the National Micro finance bank (NMB) Dar es Salaam. M. A dissertation, University of Dar es Salaam, Tanzania

Diederen, $R$ et al (1990). Diffusion of Information Technology in Banking: The Netherlands as an Illustrative case: New Explorations in the Economics of Technical change. Pinter Publishers, London. 
Esselaar, M and Associates (2001) "A Country ICT Survey for Tanzania Final Report."

Lewis, A and Davis, N (1997). Domestic and International Banking. Rhilip Allan Limited, Oxford.

Lisa, B (1996). How to use your computer. Macmillan Computer Publishing, Ottawa USA

Mayingu, A. (1999). National Workshop on Information Technology toward the $21^{\text {st }}$ Century. ICT Capacity Review in Tanzania Uhuru Hostel, Moshi Tanzania

Pagano, R. (1990). Understanding statistics in behavioral sciences, New York West Publishing.

Quiken, R (1997). “Information Technology Policy in Tanzania, Economic and Social Research Foundation". (ESRF), Dar es Salaam, Tanzania.

Rowley, j (1995) Computers for Libraries $3^{\text {rd }}$ edn- Library Association Publishing, London.

Saarinen, (1999). Information Technology and development in Banking Sector. Irwin, Singpore.

Sahay, S. and Walsh, G. (1995). Information Technology in Developing countries. A need for Theory Building. Information Development Vol 6(10): 111-124

Sanga, F (1996) Analysis of the Requirements of Information Technology Infrastructure (ITI) for THB: An extended Enterprise Perspectve. A Dissertation for degree of Masters of Science (Industrial Engineering) UDSM

Wendel, C. and Chinn R (2000) "Small business and Online lending Journal of Commercial Lending Review", Vol 15 (2): 8-10 